\section{Functions of the Tube in Sabellid Worms}

Spirographis spallanzanii Viviani and Sabella pavonina Savigny live in tubes made of a mucoid secretion mixed with mud. The animals are negatively thigmotropic, negatively geotropic and positively phototropic. The tubes, after the animals have been removed from them, cannot be stretched, but they can easily be bent. The tubes, however, are completely elastic in that they return at once to their initial shape after bending. In spite of this, the animals can bend their tubes permanently into new curves in the course of their various tropisms. To bend such a tube permanently it would be necessary to soften it; this is probably the function of the external digestion of the tube which I previously described ${ }^{1}$. The innermost lining of the tube is more elastic than the rest, and the new curvatures would be produced by a combination of softening with the deposition of new elastic tube substance within the concave side of the bend.

Removed from their tubes, Spirographis and Sabella are incapable of making new ones. Tubeless worms can be kept alive indefinitely in aerated sea-water, but in water deficient in oxygen they die, whereas worms with their tubes live in this water. We thus have the apparent paradox that a worm exposed on all sides to the water dies of asphyxia, while a worm whose body is enclosed in a tube can breathe and live.

Sabella and Spirographis can be removed from their own tubes and put into glass tubes. They line the glass tube with a secretion, and lengthen it with normal tube material. Such worms in glass tubes will live in conditions of oxygen deficit which kill naked worms. Observation of Spirographis in glass tubes has given a probable reason why naked worms are less viable than those in tubes. Inside its tube the worm executes rhythmic movements, which must continually renew the water in contact with the body. At regular intervals a swelling of the body wall, completely filling the tube, forms at the hind end of the worm; this swelling moves forwards. In the case of tubeless worms there are scarcely any such movements, and the animals are probably asphyxiated because of a stagnant layer of water in immediate contact with the body.

Tubeless worms can live in aerated water; presumably they are able to do so in spite of the absence of vigorous body movements because there is more than enough oxygen for them in the water. Worms in their tubes execute the rhythmic movements even in fully aerated water; the result of this must be that the small amount of water in the tube is continually renewed, and presumably it is necessary for the worm to renew this water even when the surrounding sea-water is fully aerated. These observations show that the tube has a second function besides that of protection : it provides the mechanical stimulus for the reflex body movements necessary for respiration.

The metabolism of Spirographis removed from its tube falls very considerably. On the same day that worms are taken out of their tubes their oxygen consumption decreases to three quarters, and on the following day to one half, of its previous value, while the ammonia excretion falls on the day of removal from the tube to four fifths of its previous value. This fall in metabolism is probably due in large part to the absence of vigorous rhythmic body movements.

Station maritime de Biologie, Tamaris, H. MUNRO Fox. and University, Birmingham.

$$
\text { Dec. } 17 .
$$

1. Fox, H. Munro, Proc. Roy. Soc., B, 112, 479 (1933).

\section{A Curious Case of Supposed Silicon Poisoning in the Swan}

DuRnNG March 1936, a swan was received from the Belle Vue Gardens, Manchester, at the Harper Adams Agricultural College, where I was working, with a note that it was one of two or three waterfowl which had all died recently on a particular pond. Post-mortem examination revealed nothing abnormal except an acute enteritis most marked in the duodenum but spreading into the middle third of the intestine. All the other organs were healthy and a bacteriological examination proved negative.

Examination of the bowel contents showed ne parasites, protozoan or otherwise, to be present, but large quantities of the water weed Potamogeton were found, and amongst them what appeared to be diatomaceous frustules. I became suspicious, and my senior officer, Mr. K. D. Downham, had a chemical analysis made of the intestinal contents. A certain percentage of silicon derived from the gizzard contents is always present in the intestine of birds, but in this case was found to be unusually high. A reference to the files showed that in the previous year, 1935, in the same month, and within four days of the then date, another swan had been received from the Gardens with precisely the same lesions. The Gardens were requested to forward a sample of the water and weed from the particular pond, which when received was found to be full of diatoms. The 'weed' consisted largely of filamentous algæ and blades of Potamogeton, encrusted with various species of diatom, notably Fragillaria and Gomphonema. These were also found free-swimming in the water. A chemical analysis of the water alone revealed an abnormally high percentage of colloidal silicon present. (I may here perhaps mention that the analyses were carried out by the analyst of the Harper Adams College, Mr. Lee).

It was therefore assumed that the enteritis in the swan was the result of mechanical irritation caused by the diatom frustules and the free silicon present in the pond.

Freshwater biologists, particularly Kathleen Carpenter in her "Life in Inland Waters", have pointed out that the spring and late winter are the times of maximum diatom increase. Their frustules cause a rise in the silicon content of fresh waters also in autumn, when Cladocera feed upon them but release their valves into the water. Birds would be killed in the spring and not in the autumn, because in spring they are greedy for the greenstuff represented by the weeds and because in addition to the diatoms there is present a large amount of free silicon released during the winter by bacterial action, namely, that which the diatoms themselves utilize in the formation of their valves. In autumn, dead shells float freely through the water, and are simply washed through the gut of water-fowl as they swallow water. I suggest that it was because the diatoms were entangled in the weed that they exerted their supposed irritative action; combined with the action of the water saturated with silicon which permeated and enveloped the algal cells.

Instructions were given that the pond was to be drained, all vegetable matter removed and its floor and sides thoroughly scrubbed and disinfected with Chloros ; and no further cases have been reported.

\section{Ernest Gray.}

East Anglian Institute of Agriculture, Chelmsford. 